\title{
Study of impact materials of Akhnoor Meteor Crater in Jammu and Kashmir (India)
}

\author{
Naseer Iqbal $^{1^{*}}$, Ajaz Ahmad $^{1}$, Tabasum Masood ${ }^{1}$, Mayank Nalinkant Vahia ${ }^{2}$ \\ ${ }^{1}$ Department of Physics, University of Kashmir, Srinagar, India; "corresponding author: iqbal@iucaa.ernet.in \\ ${ }^{2}$ Department of Astronomy and Astrophysics, Tata Institute of Fundamental Research, Mumbai, India
}

Received 12 February 2011; revised 28 March 2011; accepted 10 April 2011.

\begin{abstract}
A sample of Akhnoor meteor crater, which fell on $2^{\text {nd }}$ January 2009 in Jammu District, Jammu \& Kashmir, India, has been analyzed for elemental composition by Spectroscopic techniques. Concentrations of $\mathbf{1 7}$ major, minor and trace elements were determined. The authenticity of the meteorite sample was established by comparing its composition with those of standard meteorites/chondrite. The classification of the sample has been made by comparing the abundances and concentration ratios of elements with other known meteorites.
\end{abstract}

Keywords: Meteor Impact; Creator; Stony Meteorite

\section{INTRODUCTION}

Meteorites are generally dense, magnetic and contain oxides of metals. They show high enrichment of elements like $\mathrm{Fe}, \mathrm{Ni}$ and $\mathrm{Cr}$ compared to crustal elemental abundances. They are classified on the basis of their mineralogy, structure and chemical compositions [1-4]. The main classes of meteorites are: 1) stony meteorites constituting $92.8 \%$ of all meteorites, 2) stony iron meteorites constituting nearly $1.5 \%$ and 3 ) iron meteorites with abundance of $5.7 \%$. One of the important features of meteorite analysis is to distinguish the sample from that of a terrestrial one and to classify the meteorite regarding its origin. The standard method for identifying meteorites is to compare the chemical composition of the sample with that of the meteoritic rock previously studied. Intermetallic elemental concentration ratios like $\mathrm{Fe}+\mathrm{Mg}: \mathrm{Al}, \mathrm{Fe}: \mathrm{Ni}, \mathrm{Fe}: \mathrm{Mn}, \mathrm{As}: \mathrm{K}$ and $\mathrm{Th}: \mathrm{Sm}$ are frequently used for classification [4-6]. The elemental abundances of platinum group elements (PGEs) such as Ir, Os and Pt along with gold play an important role in the study of meteorites [6,7]. In impact craters, these elements occur in concentrations that are $20-100$ thou- sand times greater than those on the earth's crust. Such abnormal concentrations are also used as evidence for meteor impact.

On January 2009, a meteorite fall was witnessed in the Jammu division of Jammu and Kashmir (India). The meteorite arrived from north-east with high inclination path. The fireball produced by the meteoritic fall was exceptionally bright and was witnessed by the residents of the Akhnoor region of Jammu division. The fall took place on a cemented ladder as a result the formation of the crater was very small (Figures 1 and 2). From the morphological analysis we report the radius of the meteor to be roughly about $4 \mathrm{~cm}$. Samples from the crater was collected for investigation. The present study on chemical composition analysis corresponds to a meteorite sample collected from one of the craters which we have named as Akhnoor Meteor crater.

\section{METEORITIC COMPONENTS}

Meteoritic composition is the common way adopted for the confirmation of

Meteorite. The analysis of planetary material by Watson and others has marked the presence of following elemental concentrations in stony and iron meteorites in comparison with the abundance of the elements in the earth's crust [8] Table 1. A comparison of some of the elemental concentrations obtained for the meteorite sample with those of the earth's crust and an ordinary chondrite [4] is given in Table 2. There is good agreement among these values except for lanthanum, confirming that the sample under investigation is of meteoritic origin. The $\mathrm{Fe} / \mathrm{Mn}$ ratio is another indicative parameter for samples of meteoritic origin. The ratio for the present meteorite sample is 106 . This value is comparable with that of the Czech meteorite $(\mathrm{Fe} / \mathrm{Mn}=94)$, but is lower than that of the Kobe meteorite $(\mathrm{Fe} / \mathrm{Mn}=$ 175). We have compared the $\mathrm{Ni}$ to $\mathrm{Cr}$ ratio obtained in this work with some of the typical values of chondrites. The value obtained in the present case is 4.26 compared 
to the values for the chondrites which range from 4.1 to 4.8. Further inter-comparison of the analytical data with some known meteorites [1,2] was carried out with the aim to classify the Akhnoor meteorite according to its elemental content. The classification of Kobe meteorites for one of CK class are mainly based on the Si-normalized $\mathrm{Al}, \mathrm{Mg}, \mathrm{Ca}$ and $\mathrm{Ti}$ values [1]. Comparison of the $\mathrm{Al} / \mathrm{Ca}, \mathrm{Al} / \mathrm{Mg}$ and $\mathrm{Ca} / \mathrm{Mg}$ ratios in our case with those of the Kobe and Czech Meteorites show good agreement; hence we believe that the Akhnoor meteorite may be of the same class as that of the Kobe meteorite, namely CK, which is a carbonaceous.

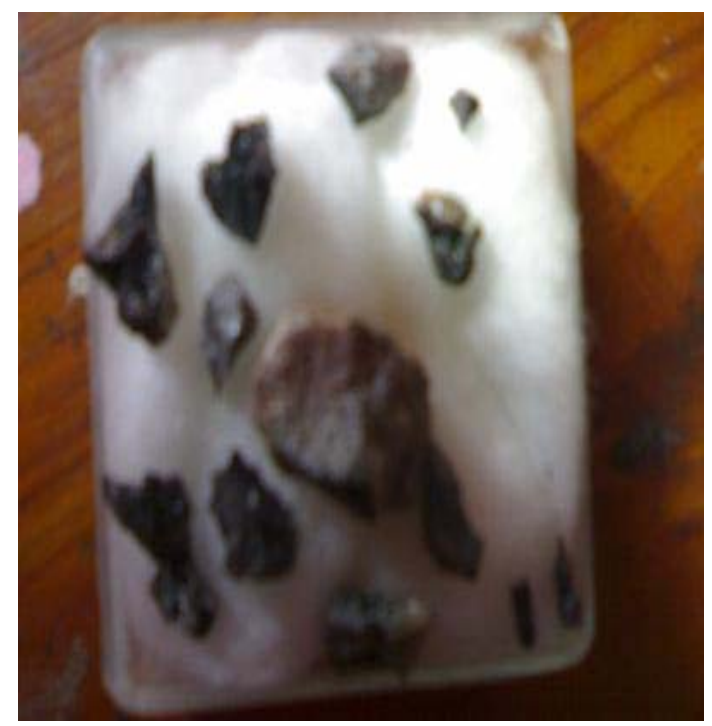

Figure 1. Samples of the meteor, collected from inside the crater.

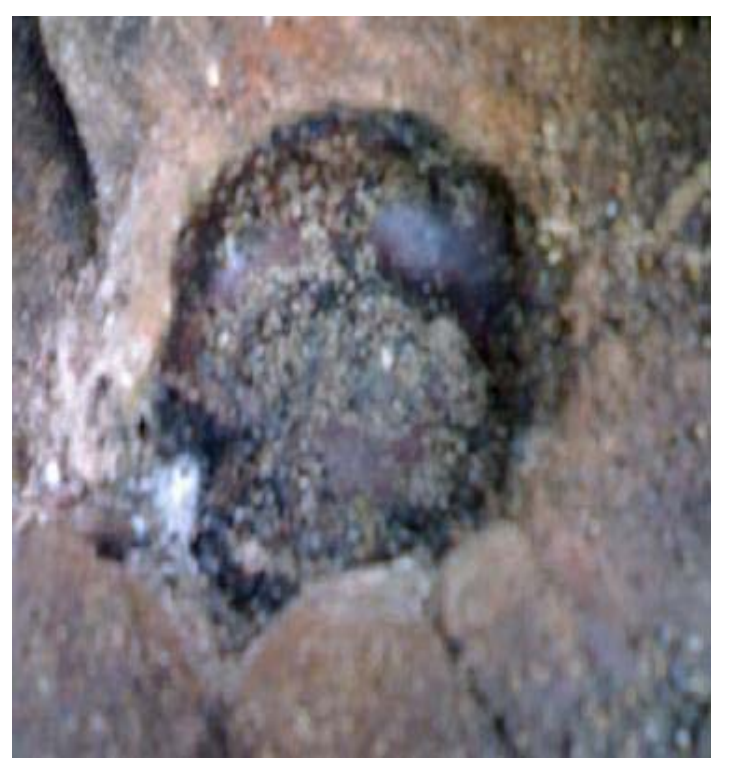

Figure 2. An outline of the Akhnoor meteor crater showing circular ring structure.
Table1. Concentration of elements of Akhnoor meteorite along with with corresponding values from Kobe and Crech meteorite.

\begin{tabular}{|c|c|c|c|}
\hline Element & $\begin{array}{l}\text { Akhnoor } \\
\text { meteorite }\end{array}$ & $\begin{array}{c}\text { Kobe } \\
\text { meteorite }\end{array}$ & $\begin{array}{l}\text { Czech me- } \\
\text { teorite }\end{array}$ \\
\hline $\mathrm{Fe}$ & 20.2 & 23.1 & 24.02 \\
\hline $\mathrm{Si}$ & 15.7 & 15.1 & 18.1 \\
\hline $\mathrm{Mn}$ & 0.19 & 0.132 & 0.255 \\
\hline $\mathrm{Cr}$ & 0.34 & 0.365 & 0.280 \\
\hline $\mathrm{Co}$ & 0.05 & 0.0714 & 0.061 \\
\hline K & 0.09 & 0.0260 & NA \\
\hline $\mathrm{Na}$ & 0.65 & 0.22 & 0.58 \\
\hline $\mathrm{Cu}$ & 0.027 & NA & 0.0179 \\
\hline $\mathrm{Mg}$ & 14.5 & 14.2 & 15.98 \\
\hline $\mathrm{Ca}$ & 1.35 & 1.63 & 1.39 \\
\hline $\mathrm{Al}$ & 1.18 & 1.29 & 1.18 \\
\hline $\mathrm{Ni}$ & 1.42 & 1.46 & 1.32 \\
\hline $\mathrm{Sc}$ & NA & NA & 7.91 \\
\hline As & NA & NA & 2.24 \\
\hline $\mathrm{Au}$ & NA & NA & 0.23 \\
\hline $\mathrm{La}$ & NA & NA & 0.44 \\
\hline $\mathrm{Eu}$ & NA & NA & 0.077 \\
\hline $\mathrm{Sm}$ & NA & NA & 0.261 \\
\hline $\operatorname{Ir}(\mathrm{mg} / \mathrm{kg})$ & 0.29 & NA & 0.603 \\
\hline $\mathrm{Br}$ & NA & NA & 9.6 \\
\hline V & NA & NA & 85.25 \\
\hline
\end{tabular}

Table 2. Average Concentration of different elements in Iron meteorites, stony meteorites and earth's crust.

\begin{tabular}{cccc}
\hline Elements & $\begin{array}{c}\text { Percentage } \\
\text { present in Iron } \\
\text { Meteorites }\end{array}$ & $\begin{array}{c}\text { Percentage } \\
\text { present in Stony } \\
\text { Meteorites }\end{array}$ & $\begin{array}{c}\text { Percentage } \\
\text { present in Earth's } \\
\text { Crust }\end{array}$ \\
\hline Iron & $90.8 \%$ & $25.6 \%$ & $4.7 \%$ \\
Cobalt & 0.59 & 0.14 & - \\
Nickel & 8.5 & 1.4 & 0.02 \\
Sulphur & 0.04 & - & - \\
Carbon & 0.03 & - & - \\
Copper & 0.02 & - & - \\
Chromium & 0.01 & 0.27 & 0.03 \\
Oxygen & - & 36.3 & 49.4 \\
Silicon & - & 18.0 & 25.8 \\
Magnesium & - & 14.2 & 1.9 \\
Aluminum & - & 1.5 & 7.5 \\
Calcium & - & 1.3 & 3.4 \\
Sodium & - & 0.6 & 2.6 \\
Manganese & - & 0.18 & 0.08 \\
Potassium & - & 0.13 & 2.4 \\
Titanium & - & 0.10 & - \\
Samarium & - & - & 0.12 \\
Europium & - & & \\
Phosphorus & 0.17 & - & - \\
\hline
\end{tabular}




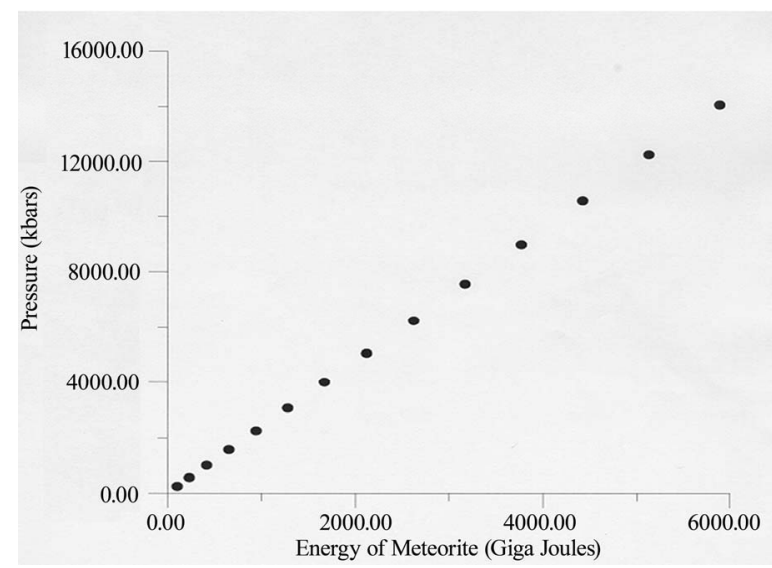

Figure 3. Graph plotted between Energy and Pressure [9].

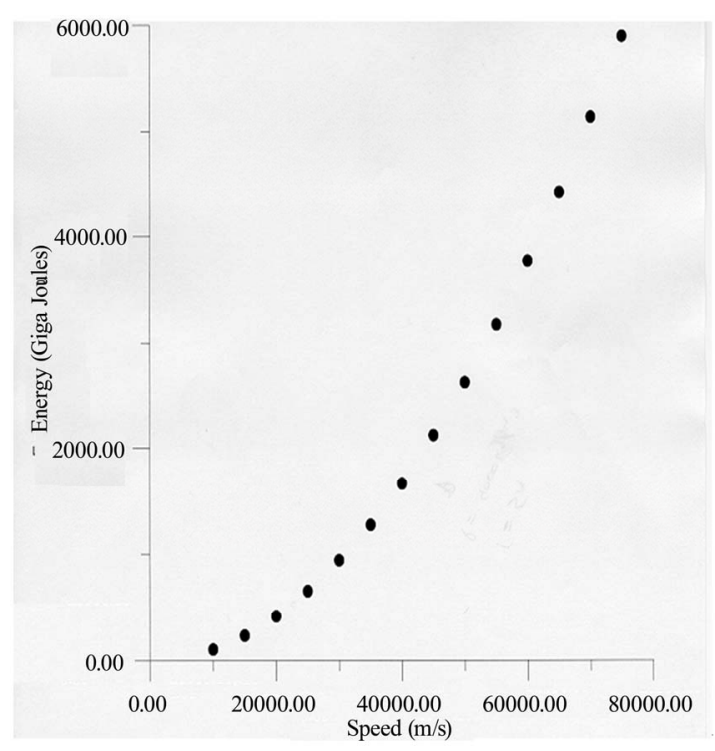

Figure 4. Graph plotted between speed and Energy [9].

Iridium is present in small amounts in the earth's crust and upper mantle, but is more abundant in both the earth's core and meteorites. We observed Ir in the present case and its concentration $(0.29 \mathrm{mg} / \mathrm{kg})$ is $\sim 290$ times higher than that in the earth's crust. The concentration values obtained for all the elements were compared with their respective crustal elemental abundance values. It is observed that the values corresponding to $\mathrm{Fe}$, $\mathrm{Mg}, \mathrm{Cr}$ and $\mathrm{Ni}$ are higher than the crustal values, whereas the values for elements like $\mathrm{Al}, \mathrm{Ca}$ and $\mathrm{Na}$ are lower. Data obtained based on chemical composition claims that the said sample collected is of meteoritic origin.

\section{ANALYSIS}

While analyzing the graph plotted between the radius of the Meteor and the corresponding energy of the Meteor we report here that the energy associated with

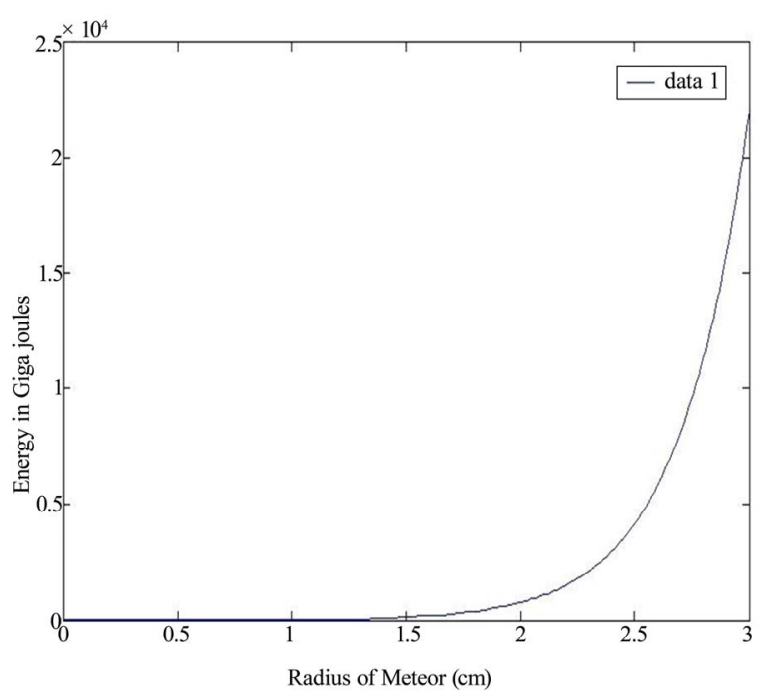

Figure 5. Graph plotted between Radius of Meteor and Energy. The value has been calculated at rough radius of the meteor $2.0 \mathrm{~cm}$.

the Akhnor Meteor crater is approximately 1,000 GJ [9] (Figures 3-5). By comparing the Energy of the Meteorite with the speed and the pressure exerted by the meteorite and by using the graphs reported by Mark and others [9], plotted between the Energy of the meteorite with pressure exerted by it and the Energy with speed, we reveal here an another remark that the Meteor has hit the surface of the Earth with a speed of $30,000 \mathrm{~m} / \mathrm{s}$ and has exerted a pressure of $2128 \mathrm{kbars}$.

\section{RESULTS}

The following conclusions have been drawn about the Akhnoor Meteor crater.

The Akhnoor meteor crater is a stony Meteorite.

The approximate energy of the meteorite had been 1000 GJ.

The meteor had hit the earth's surface with a velocity of $30,000 \mathrm{~m} / \mathrm{s}$ and exerted a pressure of $2128 \mathrm{kbars}$.

\section{ACKNOWLEDGEMENTS}

The Authors are grateful to the Jamestiji Tata trust Mumbai for their support in Carrying out this work. Thanks are also due to Sheri Kashmir University of Agricultural Sciences and Technology, University Scientific instrumentation Centre (University of Kashmir Srinagar India) and Department of Geology and Geophysics University of Kashmir for their help in carrying the necessary scientific investigations. Thanks are also due to IUCAA Pune India for their hospitality in preparing this manuscript.

\section{REFERENCES}

[1] Oura, Y., Ebihara, M., Yoneda, S. and Nakamura, N. 
(2002) Chemical composition of the kobe meteorite; neutron-induced prompt gamma ray analysis study. Geochemical Journal, 36, 298-307.

[2] Randa, Z., Kucera, J. and Soukal, L. (2003) Elemental characterization of the new Czech meteorite 'Moravka' by neutron and photon activation analysis. Journal of Radioanalytical and Nuclear Chemistry, 257, 275-283. doi:10.1023/A:1024767309558

[3] Ebihara, M., Shinotsuka, K. and Kong, P. (1996) Chemical composition of Martian meteorites. 61st Annual Meteoritical Meeting, Germany.

[4] Larimer, J. W. (1971) Composition of the earth: Chondritic or achondritic? Geochimica et Cosmochimica Acta, 35, 769-786. doi:10.1016/0016-7037(71)90125-6
[5] Korotev, R.L. (2004) Lunar meteorites. Department of Earth and Planetary Sciences, Washington University, St. Louis.

[6] Ganzalez, M.A. (2003) Of meteors and meteorites. North Dakota Geological Survey, USA.

[7] Palme, H., Janssens, M.-J., Takahashi, H., Anders, E. and Hertogen, J. (1978) Meteoritic material at five large impact craters. Geochimica et Cosmochimica Acta, 42, 313323. doi:10.1016/0016-7037(78)90184-9

[8] Nininger, H.H. (1992) An introduction to meteoritics. Dover Publications, Inc., New York.

[9] Meteorite phenomenon, the cratering process quantized. http://www.umich.edu/ gss265/meteor.htm 